\title{
A SALA DE RECUPERAÇÃO PÓS-PARTO ENQUANTO CONTEIXTO COMPORTAMENTAL: UMA TENTATIVA DE AVALIAÇÃO *
}

\author{
Zaida A. S. Geraldes Soler ** \\ Nilce Pinheiro Mejias***
}

SOLER, Z.A.S.G. \& MEJIAS, N.P. A sala de recuperação pós-parto enquanto contexto comportamental: uma tentativa de avaliação. Rev. Esc. Enf. USP, São Paulo, 24(3):329-344, dez. 1990.

Considerando a importância do ambiente enquanta contexto comportamental, este trabalho mostra uma primeira tentativa no sentido de avaliar uma sala de recuperação pós-parto imediato, usando como procedimento a observação sistemática. Como objeto de observação foram também consideradas as interações profissional-paciente $e$ paciente-paciente. As informações obtidas sugerem que a alteração de alguma.s variáveis ambientais fisicas e programáticas poderão contribuir para uma maior eficácia na assistência às pacientes.

UNITERMOS: Ambiente de instituições de saúde. Sala de recuperação. Parto.

Ao se tratar de diagnóstico dentro de um ponto de vista tradicional, considera-se a psicopatologia como resultante de variáveis intraorganismicas relativamente estáveis que residem na pessoa. Não que se ignore a importância do papel dos fatores ambientais, porém a ênfase maior é dada ao indivíduo e a causas intraorganismicas.

Em contraste com essa ênfase, a avaliação comportamental mantém comumente um ponto de vista situacional ou interacional. Nesses termos o comportamento - encarado como uma amostra de respostas em dada situação de avaliação - é uma resultante quer de fatores ambientais, quer de fatores ambientais interagindo com variáveis organismicas. Além disso, parece de interesse acrescentar, conforme palavras de NELSON \& HAYES ${ }^{18}$, que nas últimas décaàas surgiram, na área de avaliação, duas direções novas e bastante ligadas entre si: a avaliação ambiental e a avaliação comportamental. Na avaliação ambiental, o foco de atenção recai sobre as caracteristicas comportalmente

- Baseado em trabalho de campo realizado por Zaida A. S. Geraldes Soler, em disciplina ministrada por Nilce Pinheiro Mejias em curso de p6s-graduaça do Instituto de Psicologla da Universidade de săo Paulo.

* Do programa de pos-graduacío, nivel de doutorado, da Escola de Fnfermagem da Universidade de sto Paulo. Bolsigta do CNPq.

*** Do Departamento de Psicologia Clínica do Instituto de Psicologia da Universidade de Bá Paulo. 
relevantes dos ambientes em que o comportamento ocorre, em contraste com a ênfase mais tradicional sobre variáveis pessoais.

Consoante com este ponto de vista, TWARDOSZ *, apresentando uma revisão de numerosas pesquisas, trata da importância das variáveis envolvidas na organização ambiental para a modificação de comportamento, citando especificamente as variáveis físicas (incluindo, entre cutras as características de arquitetura. móveis, equipamentos, sinalizações), as sociais e as programáticas (presença e localização de pessoas, divisão de suas responsabilidades, horário de atividades, organização de tarefas e semelhantes). A autora aponta três razões principais para a importância dessas variáveis:

1. a eficácia do controle de contingências e outros procedimentos educacionais dependem, em grande parte, da organização do ambiente para apoiá-los;

2. alguns problemias podem ser tratados ou prevenidos através da organização do ambiente em que ocorrem;

3. a atenção para a organização das variáveis ambientais pocle contribuir para a organização e operação de um ambiente mais humano c para melhorar a qualidade de vida.

Inúmeras são as situações em que se realizam trabalhos envolvendo variáveis ambientais, como hospitais, escolas, creches e, enfim, instituições as mais variadas. Nos últimos anos a área de saúde, segundo WHITEHEAD et alii ${ }^{28}$, vem prestando uma atenção cada vez maior às interrelações entre ambiente e comportamento. $\mathrm{E}$. de fato uma revisão da literatura a partir de 1982, sem pretender ser exaustiva, mostra várias pesquisas envolvendo variáveis ambientais realizadas sobretudo em hospitais psiquiátricos.

MAC DONALD et alii ${ }^{13}$ verificaram, scqüencialmente, três trätamentos comportamentais numa enfermaria de pacientes geriátricos, psiquiátricos: o reforço contingente às atividades do paciente, as indicações (prompting) para as atividades de pacientes inativos e a reprogramação do arranjo físico da sala de estar. Os três tratamentos resultaram em aumento de atividade dos pacientes. WHITEHEAD et alii ${ }^{28}$, partindo da hipótese de que alterações do ambiente estariam correlacionadas com mudanças no comportamento social e reduziriam a patologia, procuraram avaliar o efeito da redistribuição de camas numa unidade psiquiátrica. Os resultados indicaram que o rearranjo do ambiente correlacionava-se com mudanças comportamentais favoráveis do ponto de vista clínico. STAHLER et alii ${ }^{23}$ reformaram e remodelaram a sala de estar de uma enfermaria geriátrica psiquiátrica para propiciar aos pacientes condições mais humanas e melhorar seu comportamento adaptativo. Para verificar a eficácia da reforma, compararam os dados obtidos com pacientes dessa sala com dados obtidos com pacientes de outra sala não remodelada. Os autores verificaram que, imediatamente após a remodelação, houve aumento da interação paciente-staff. mas notaram também que no período logo após a intervenção houve aumento 
de hostilidade e tensão bem como a diminuição de sociabilidade e de comportamentos de automanutenção. No entanto, cinco semanas depois, os comportamentos patológicos diminuiram a um nivel abaixo daquele mostrado anteriormente à reforma. Nenhuma alteração foi observada no grupo comparativo. Outro autor preocupado com o rearranjo da sala de estar é STEVE ${ }^{24}$ que estudou os efeitos de uma intervenção ambiental a curto prazo, introduzindo alterações no arranjo de móveis de uma sala de estar de uma enfermaria de um hospital de segurança máxima. Os resultados mostraram que o emprego de técnicas de baixo custo como essa podem introduzir mudanças modestas em ambientes de enfermaria $\mathrm{ccm}$ clientes mais difíceis. KELLY \& OSTREICHER ${ }^{12}$ preocuparam-se especificamente com a influência da posição de cama dos pacientes. Esses autores realizaram uma revisão de registro de 73 sujeitos em condições de reabilitação, após acidente vascular cerebral em hemisfério direito. Sua preocupação foi verificar se os sujeitos com as camas dispostas de forma que o lado direito de seu corpo (o não afetado) estivesse voltado para eventos e itens importantes teriam melhora maior do que aqueles com o lado esquerdo do corpo (o afetado) voltado para itens e eventos importantes. Um outro grupo de 64 pacientes com acidente vascular cerebral do hemisfério esquerdo foi utilizado como comparação. Para nenhum dos grupos a disposição da cama pareceu ter qualquer influência sobre os pacientes. MC PHERSON et alii ${ }^{16}$ procuraram avaliar os efeitos de mudança para acomodações mais amplas sobre pacientes de uma enfermaria psiquiátrica geriátrica. Contrariando as expectativas, os resultados mostraram que o aumento de espaço não resultou em aumento de interação social e atividades construtivas. SCHAFER ${ }^{22}$, discute um programa de enfermagem para avaliação diagnóstica e de apoio a pacientes com Alzheimer. Nesse programa, a enfermeira adaptava o ambiente físico e social ao paciente ao invés de pedir ao paciente que se adaptasse à rotina da instituição. Era o paciente que se tornava, então, critério de funcionamento da unidade. A conclusão é de que, criando-se um ambiente em que o paciente com a moléstia de Alzheimer se sinta mais seguro e confortável, pode-se incentivá-lo a continuar usando as capacidades que tem por tanto tempo quanto possivel. Ainda no mesmo ano, WINKEL \& HALAHAM ${ }^{29}$ fizeram uma revisão de pesquisas sobre o papel do ambiente físico na prevenção e redução de problemas sociais e psicológicos enfrentados por pacientes em caso agudo. internados em instituições psiquiátricas. Segundo esses autores, fatores considerados importantes para estratégias preventivas incluem a planta e o planejamento do ambiente hospitalar. o relacionamento social no hospital e niveis de estimulação ambiental. De 1987 é o trabalho de INGSTAD \& GUNNAR ${ }^{11}$ que, preocupados com a atitude do staff, verificaram, o efeito de algumas mudanças ambientais, como alteração na posição de cadeíras, na rotina de serviço e na distribuição de material utilizado na execução de atividades. A atitude do staff melhorou em relação aos pacientes durante as refeições, nos momentos de troca de roupa e na interação social. Ainda no mesmo ano e preocupados com as relações entre variáveis físicas e comportamento, VERDERBER \& REUMAN ${ }^{27}$ procuraram verificar o efeito 
produzido pelas janelas, comparando as reações do staff e dos pacientes à presença de janelas e fatores associados a estas. Os dados obtidos revelaram que os pacientes eram negativamente influenciados por escassez de janelas na sala, se comparados ao staff. Além disso, pacientes com dificuldades de visão, paralisados e imóveis, bem como os "não brancos", eram afetados quando a uma distância de mais de 10 pés, por periodos relativamente longos. Quanto ao staff. eram afetadas as pessoas que trabalhavam mais do que 40 horas por semana ou com terapia física.

No Brasil vários são os trabalhos voltados para a interrelação comportamento-ambiente realizados em hospitais, entre os quais podem ser citados o de QUEIROZ ${ }^{20}$ que implantou numa ala de pacientes psicóticos crônicos um programa de treino de atendentes em técnicas de modificação de comportamento com a utilização de um sistema de economia de fichas. Esse trabalho, que envolveu várias adaptações administrativas, incluiu também a montagem de uma oficina de trabalho. Embora seu objetivo principal tenha sido o desenvolvimento de respostas de higiene, seus resultados mostraram também o desenvolvimento de respostas envolvidas com atividades de educação física, trabalho na oficina e assistência a TV. O de CARVALHO ${ }^{2}$, realizado num pavilhão de crianças de um hospital psiquiátrico, onde a autora introduziu mudanças no ambiente com enfoque nas atividades de banho e alimentação, visando propiciar condições para alterações dos comportamentos das crianças. Os resultados mostraram que, introduzidas as alterações, houve melhora acentuada no repertório comportamental de crianças e atendentes. O de GORAYEB ${ }^{6}$ realizado junto ao Departamento de Ginecologia, Obstetrícia e Pediatria de um hospital-escola, em duas enfermarias para puérperas, para verificar diferenças entre o alojamento conjunto, onde os bebês ficavam ao lado das mães enquanto permaneciam no hospital, e o alojamento tradicional, em que os bebês permaneciam nos berçários e eram levados para a companha das mães somente nas horas das mamadas. Os estudos revelaram que o fato de 0 bebê permanecer junto à mãe não era a variável que controlava os comportamentos definidos como afetivos. Os dados indicaram também que algumas das vantagens atribuídas ao alojamento conjunto precisam ainda ser revistas. $O$ de MAURO ${ }^{15}$, realizado a nivel de projeto, envolve dois estudos em hospital de doenças do aparelho locomotor, em que o autor procurou estabelecer relações funcionais claras entre as características dos equipamentos hospitalares e aspectos relevantes do comportamento do usuário e do staff. No estudo 1 desenvolveu o projeto de um painel divisório móvel que, além de separar as camas, deveria servir para guarda de objetos pessoais do paciente. e no estudo 2 , o projeto de uma cama rolante ortopédica para adultos. As técnicas de investigação utilizadas foram a observação direta do comportamento registro de incidentes críticos e simulação de ambientes. O de ZANNON ${ }^{30} \mathrm{em}$ que a autora, tendo em vista a atuação do psicólogo em termos de uma promoção do desenvolvimento ambiental voltada para a prevenção e a promoção do desenvolvimento infantil, faz a descrição de um levantamento preliminar de condições de atendimento à criança no setor de 
enfermaria pediátrica de dois hospitais. Os procedimentos utilizados foram a observação direta dos comportamentos das crianças hospitalizadas e de variáveis do contexto ambiental, e entrevistas com o pessoal para obter informações sobre as condições gerais de atendimento.

A maioria dos autores citados parece preocupada em mostrar relações estreitas entre algumas variáveis ambientais e o comportamento, visando o bem estar de pessoas hospitalizadas. Os outros, sobretudo os brasıeiros, parecem partir do pressuposto de que tais relaçōes existem. procurando verificar sob que circunstâncias podem ser mais eficazes quando envolvidas em programas de intervenção.

Partindo do pressuposto de que o comportamento é uma resultante quer de fatores ambientais, quer de fatores ambientais interagindo com variáveis organismicas, o trabalho que se segue constitui uma primeira tentativa de avaliação das condições de uma sala de recuperação pós-parto num hospitalescola.

Diversos autores são unânimes em relatar que o pós-parto imediato, ou quarto periodo de parto, tem caracteristicas fisiológicas que devem ser conhecidas para que as intercorrências anormais sejam tratadas rapidamente. Esse período foi definido por GREENBERG ${ }^{7}$, como a primeira hora subseqüente à dequitação (expulsão da placenta).

BARBOSA 1 , CLAUSE ${ }^{3}$, DELASCIO \& GUARIENTO 5 , GRELLE \& AMARAL ${ }^{8}$, HESTER ${ }^{9}$, HICKS ${ }^{10}$, MACKENZIE ${ }^{14}$, MOTTOS \& MARETTI ${ }^{17}$, NEME ${ }^{19}$, REZENDE ${ }^{21}$, ZIEGEL \& CRANLEY ${ }^{31}$, entre outros, afirmam, ainda que não se pode negligenciar a vigilância da mulher nesse período, visando, principalmente, a detecção precoce de uma hemorragia, assim como o pronto atendimento de suas conseqüências. Diante disso preconizam alguns procedimentos de rotina que devem ser realizados com todas as puérperas a cada 10 a 15 minutos. $\mathrm{O}$ propósito destes controles é reunir informações sobre o estado geral das puérperas, diagnosticar problemas potenciais e proceder à intervenção necessária com rapidez e eficiência.

Em nosso meio, os controles das puérperas são feitos, comumente, pela enfermeira-obstctra ou por uma pessoa da equipe de enfermagem. Quanto ao local de atendimento, diverge durante esse periodo, embora, na maioria das maternidades da cidade de São Paulo, as puérperas sejam transferidas imediatamente da sala de parto para o seu leito na unidade de puerpério. Entretanto, pode ainda ocorrer, em alguns hospitais. que elas permaneçam em macas, por um tempo não determinado, nos corredores do centro obstétrico antes do encaminhamento ao puerpério, ou ainda, sejam instaladas em macas em uma sala do interior do centro obstétrico, local usualmente chamado de sala de recuperação pós-parto.

Independentemente do local, o que Soler * tem verificado em sua vida profissional é que, na maior parte das vezes, negligenciam-se

* A primeira autora deste trabalho. 
alguns o.spectos psicológicos no atendimento prestado às puérperas. No entanto, através de observações não sistemáticas, ela teve ocasião de observar agitação, queixas de dor, de desconforto, de cansaço e de fome, além de pedidos de informações sobre seu estado, o de seu filho e o da família que a aguarda. Por outro lado, observou ainda que algumas puérperas mostraram-se sonolentas, apáticas' sem solicitar ajuda ou apresentar queixa, permanecendo em silêncio até serem encaminhadas à unidade de puerpério. Essas pacientes, deixadas a si mesmas, dificultam a interação com as pessoas que as ossistem e podem, por isso, ser mais negligenciadas em seus controles. Soler ohservou também, que algumas são instaladas em local inadequado e, por essa razão, de acesso mais difícil a uma assistência freqüente.

Ante o exposto a permanência da puérpera numa sala especialmente estruturada para o seu atendimento com a presença permanente de um profissional de enfermagem vigilante deverá contribuir para uma maior presteza na resolução de problemas observados assim como propiciar uma interação inter-pessoal que facilite uma assistência mais abrangente. $\dot{E}$, sem dúvida, com base em considerações como essas, que alguns hospitais proporcionam às puérperas uma sala especial de recuperação pós-parto.

Tendo em vista a avaliação ambiental como o levantamento de caracteristicas comportalmente relevantes dos ambientes em que o comportamento ocorre, conforme DANNA \& $\operatorname{MATOS}^{4}$ e NELSON \& HAYES ${ }^{18}$, este trabalho tentou verificar se uma dada sala de recuperação pós-parto imediato constituía uma situação propiciadora, de um lado, para os comportamentos preconizados para as enfermeiras e, de outro, para o bem estar da puérpera. Em outras palavras, este trabalho constituiu uma primeira tentativa para avaliar se as condições ambientais de uma sala de recuperação pós-parto imediato estariam congruentes com os objetivos que orientaram seu planejamento e montagem, tendo em vista futuras alterações para facilitar ao máximo tal congruência.

\section{METODO}

\section{- AMBIENTE E SUJEITOS}

Este estudo foi realizado em um hospital-escola de médio porte do municipio de São Paulo, que presta assistência hospitalar e ambulatorial em várias especialidades médicas, dedicando-se também ao ensino e à pesquisa.

$O$ ambiente específico onde se realizou este estudo foi a sala de recuperação pós-parto instalada no interior do centro obstétrico deste hospital-escola.

A sala de recuperação pós-parto media aproximadamente 4.5 por 3.5 metros e continha o seguinte material de atendimento: um aparelho de oxigênio e de ar comprimido, três suportes para soro e um esfignomanômetro "de carrinho", além dos materiais (medicamentos, seringas, 
agulhas, equipos e frascos de soro) que estavam acondicionados numa mesa-armário. Como mobiliário fixo continha: uma cama com grades, a mesa-armário para reserva de medicamentos já citada, um "hamper", um balde para coleta de lixo. Outros elementos eram: um relógio de parede, um interfone e um aparelho de ar condicionado. A iluminação era artificial, havendo 9 lâmpadas fluorescentes na sala. Como mobiliário não permanente constavam as macas, onde permaneciam as puérperas até serem transferidas, nas mesmas para a unidade de puerpério.

Os sujeitos deste estudo foram duas puérperas internadas na sala de recuperação pós-parto assim como as profissionais de enfermagem que as atendiam, ou seja, uma enfermeira, uma auxiliar de enfermagem, uma aluna da habilitação em enfermagem obstétrica.

As puérperas estavam deitadas em decúbito dorsal-horizontal, em macas com as grades levantadas. Uma delas tivera o parto resolvido normalmente, enquanto a outra fora submetida a parto cesárea. Estavam de camisola hospitalar e cobertas com um lençol.

As profissionais de enfermagem não permaneceram na sala, entrando e saindo, ficando no local somente nos momentos de execução de alguma tarefa.

\section{- PROCEDIMENTO}

O procedimento utilizado para a coleta de dados sobre o ambiente físico e social da sala de recuperação foi a observação com registro cursivo.

Foi realizada apenas uma observação por se tratar de uma primeira tentativa para verificar a possibilidade de se realizar o tipo de avaliação proposto.

Foram os seguintes, os itens considerados para observação: *

1. data, horário e tempo de observação;

2. dados relacionados ao ambiente físico: dimensões da sala, iluminação, temperatura ruído, mobiliário materiais e equipamentos disponiveis;

3. a. dados relacionados ao ambiente social: identificação das pessoas presentes no local e descrição suscinta das atividades que realizavam,

b. dados específicos relacionados aos comportamentos dos sujeitos do estudo, tendo sido registrado o seguinte: o que as puérperas faziam (o que incluia sua movimentação e o que diziam) quais as atividades realizadas pelas profissionais de enfermagem e, nos casos de interação, quem a iniciava, a quem se dirigia e qual era o tipo de ação. A interação foi considerada como "um

* Este roteiro teve como base sugestões de DANNA \& MATTOS 4. 
episodio de contacto entre duas pessoas, onde existe o comportamento de um emissor $e$ um comportamento de um receptor, em resposta do do emissor" (STTRBULOV ${ }^{25}$ ).

Durante a coleta de dados, a fim de justificar a presença de outra pessoa no ambiente, a observadora * agiu como se estivesse avaliando as condições da sala, verificando seus aspectos gerais bem como o funcionamento dos aparelhos e os materiais para uso.

A duração da observação do comportamento das pacientes e profissionais foi o tempo de permanência das puérperas na sala, ou seja. cerca de duas horas. As observações e registro das condições físicas foram feitas em outro momento.

Para a avaliação proposta das condições ambientais da sala de recuperação pós-parto foram consideradas as suas caracteristicas físicas e programáticas, no sentido de destacar os elementos que poderiam estar dificultando o bem estar das puérperas o desempenho satisfatório dos profissionais de enfermagem e a interação paciente-profissional.

\section{RESULTADOS E DISCUSSĀO}

\section{- CONDIÇOES FISICAS DO AMBIENTE}

1. Relativamente ao bem estar geral das puérperas foi observado o seguinte:

- Apesar de ter sido relatada uma temperatura de $23^{\circ} \mathrm{C}$, o local estava frio. A sensação de frio foi referida algumas vezes pelas pacientes e constatada pela própria observadora;

- $\mathrm{O}$ ar condicionado ligado emitia um barulho que perturbava a acuidade auditiva no local e portanto também poderia estar perturbando as puérperas. Supôs-se a má acuidade auditiva devido a interrogações repetidas nas interações verbais entre as pessoas presentes e à dificuldade da própria observadora em acompanhar tudo o que se dizia no ambiente;

- A luz das lâmpadas fluorescentes incidiam diretamente sobre as olhos das pacientes, dada a posição das macas onde estavam deitadas. Este fato parecia levá-las a mudar, por várias vezes, a posição da cabeça e/ou fechar os olhos.

As puérperas estavam nas macas em decúbito dorsal horizontal, sem qualquer elevação da cabeceira, o que dificultava que olhassem e, conseqüentemente, vissem o que se passava na sala ou as pessoas presentes na sala, a não ser que estas se aproximassem. Além disso, a posição das macas dificultava a visão das puérperas entre si o que parecia perturbá-las quando conversavam.

* A observação foi realizada pela primeira autora, solfrr. 


\section{Relativamente às tarefas das profissionais:}

Conforme foi observado, os materiais e equipamentos disponiveis nesta sala de recuperação pós-parto eram adequados e suficientes para os cuidados da puérpera no quarto periodo de parto. No entanto algumas alterações talvez possibilitassem maior permanência da profissional de enfermagem na sala e, conseqüentemente, uma assistência mais constante com menos interrupções. As mudanças envolveriam:

- A presença de armário para roupa (lençóis, camisolas e pensos perineais) para que, na ocorrência de troca, não fosse necessário que a profissional saísse da sala em busca do material;

- $O$ uso de um local próximo à sala de recuperação para acondicionar as comadres. No quarto periodo do parto um dos cuidados previstos é a verificação da repleção vesical. No entanto, segundo foi observado, as comadres permaneciam no vestiário feminino, distante da sala de recuperação.

- A colocação de uma pia na sala, para a lavagem das mãos da profissional entre os cuidados de uma e outra puérpera, poderia evitar que ela se deslocasse até o lavabo do centro obstétrico, conforme foi observado.

- A presença de uma cadeira para a profissional sentar-se, quer durante as anotações na papeleta, quer, principalmente quando não havia tarefas específicas a realizar, poderia ter mantido a profissional maior tempo na sala para dar maior atenção às necessidades das pacientes. Conforme foi observado nos intervalos entre tarefas, as profissionais ficavam fora da sala circulando ou sentadas em banquetas próximas ao balcão de comunicação entre o centro obstétrico e a sala pré-parto.

O Quadro I, apresenta os comportamentos observados. As pessoas foram assim identificadas: PPN - paciente de parto normal; PPC paciente submetida a cesareana; $\mathrm{E}$ - enfermeira; $\mathrm{AE}$ - auxiliar de enfermagem; $\mathrm{A} 1 \mathrm{E}$ - aluna de enfermagem.

Conforme o Quadro I, pode-se verificar que o repertório de comportamentos apresentados pelas puérperas e pelos profissionais de enfermagem foi bastante limitado, o que talvez seja natural na situação. As interações verbais foram mais numerosas entre as puérperas, sendo que as profissionais de enfermagem interagiram verbalmente maior número de vezes entre si do que com as puérperas. Os comportamentos das puérperas sugerem impaciência e desconforto (queixavám-se, perguntavam as horas, viravam a cabeça, dobravam os joelhos, esfregavam os pés), enquanto os comportamentos das profissionais de enfermagem limitaram-se quase exclusivamente à execução de procedimentos técnicos (mediam pressão arterial, anotavam na papeleta olhavam para 0 gotejamento do soro etc.).

Para melhor ilustrar o ocorrido são apresentados, a seguir, alguns exemplos dos diálogos registrados durante o período de observação. 


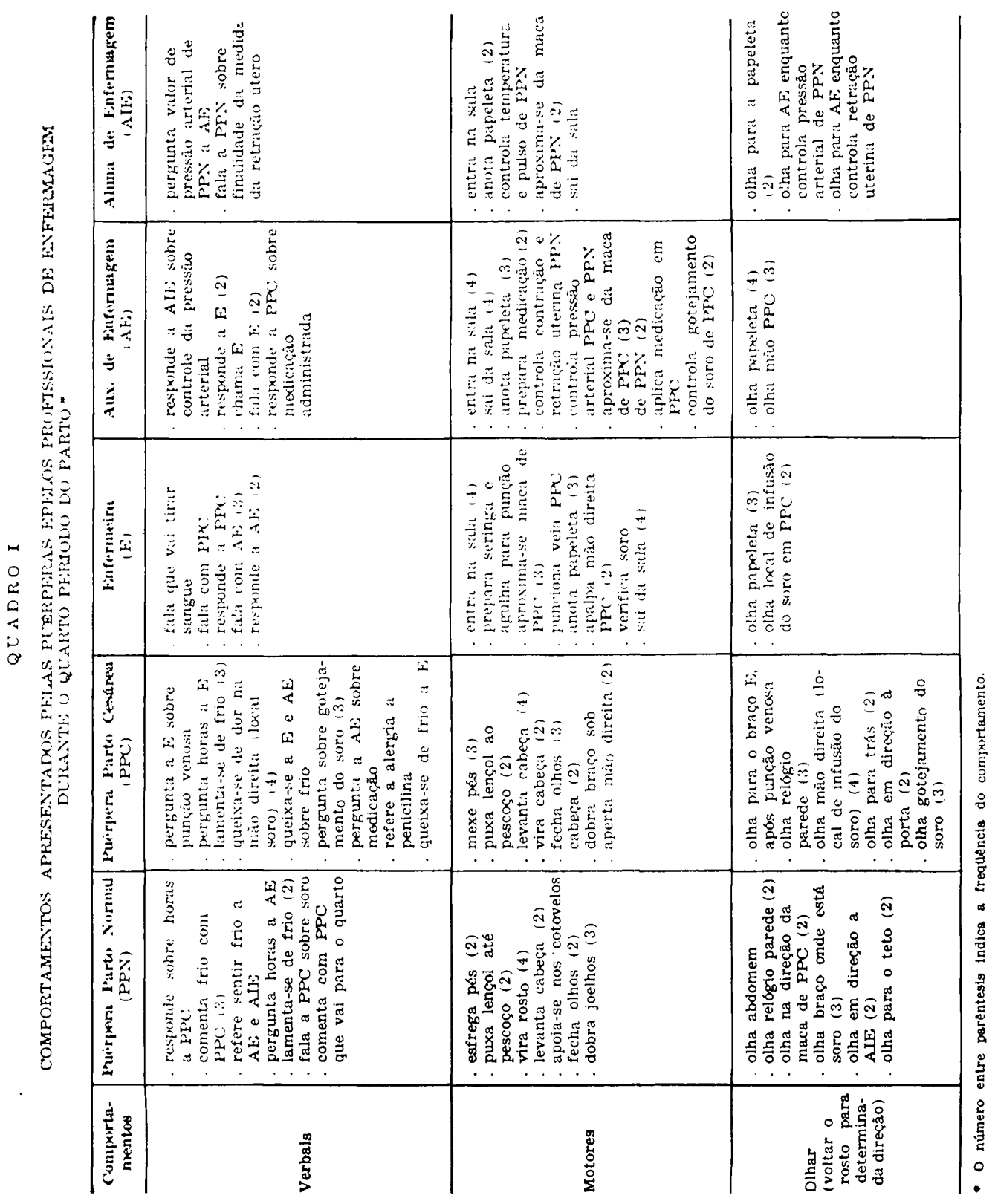




\section{Exemplo I}

A auxiliar de enfermagem está preparando a medicação e a aluna de enfermagem está olhando para a papeleta da paciente de parto normal. Entra a enfermeira na sala, vai até a mesa-armário, pega uma seringa e uma agulha e fala:

E. - "a senhora vai me xingar, mas eu tenho que tirar sangue". Aproxima-se do lado esquerdo da maca de PPC.

PPC - "é de mim? tem que tirar sangue?"

$\mathrm{E}$ coloca o garrote no braço esquerdo de $\mathrm{PPC}$, punciona a veia, retira o sangue, desamarra o garrote e coloca algodão no local da punção.

- “Viu, não.doeu muito".

PPC levanta a cabeça, olha para o braço e pergunta:

- "Que horas são?"

Ninguém responde. Ela vira a cabeça à direita em direção ao relógio de parede (está parado).

E anota na papeleta da paciente PPC e sai da sala com a seringa com sangue nas mãos.

PPC - "Que horas serão?" . .

PPN - "Não sei, esse relógio não tá certo".

$\mathrm{PPC}-$ - $O$ quê? É, deve ser tarde".

PPN - "Ah! ...Ai que frio". Puxa o lençol até o pescoço, esfrega um pé contra o outro.

Pelo que se pode observar. não houve na ação de $\mathrm{E}$ o cuidado de orientar PPC sobre o procedimento realizado. Houve apenas a interação necessária entre E e PPC para a coleta de sangue e uma breve interação verbal entre as puérperas.

Exemplo II

AE faz os controles da pressão arterial de PPC e PPN. A1E observa medir as pressões. Está com a papeleta de PPN nas mãos.

- "Quanto deu?"

$\mathrm{AE}$ responde a $\mathrm{A} 1 \mathrm{E}$ o valor constatado e esta faz anotações na papeleta de PPN.

PPC - "Estou com frio".

PPN - "Ahn?"

PPC levanta a cabeça, olha para trás. - "Está frio".

PPN - " $E$. . , está frio".

Verifica-se, neste exemplo, que a ação interpessoal entre os profissionais e as puérperas deveu-se exclusivamente à realização do controle 
de pressão arterial. As pacientes não foram informadas sobre a tarefa realizada e suas queixas não foram ouvidas por $\mathrm{AE}$ e $\mathrm{A} 1 \mathrm{E}$. Houve uma breve interação verbal entre PPC e PPN.

\section{Exemplo III}

A1E olha a papeleta de PPN e sai da sala. AE prepara medicação. PPC - "Ai, que dor. O soro está correndo?"

AE aproxima-se da maca de PPC com a seringa com medicamento nas mãos.

Verifica se não há infiltração do soro. Desconecta o equipo para aplicar a droga prescrita.

PPC olha para o local de infusão do soro.

- "É penicilina? ... sou alérgica a penicilina".

$\mathrm{AE}-$ - $E$ antibiótico". Em seguida, conecta o equipo e controla o gotcjamento do soro. Faz anotações na papeleta e sai da sala.

Neste exemplo, a interação entre $\mathrm{AE}$ com $\mathrm{PPC}$ foi suscinta. AE não teve o cuidado de explicar a PPC que, apesar de estar aplicando antibiótico, este não era penicilina. Além disso, AE constatou que estava correta a infusão do soro, mas não informou este fato a PPC. Vale ressaltar que, depois do episódio as puérpuras permaneceram sozinhas na sala por alguns minutos. Nessa ocasião fizeram algumas tentativas de interação verbal, mas tiveram dificuldades dado o barulho do ar condicionado e, aparentemente, também devido ao fato de não conse. guirem olhar-se.

\section{Exemplo IV}

E entra na sala com $\mathrm{AE}$ e diz a $\mathrm{AE}$ para levar PPN.

PPN ao aproximar-se da maca de PPC diz para PPC:

- "Acho que vou para o quarto".

PPC levanta a cabeça, deita-se novamente. PPN sai da sala, com a maca empurrada por AE.

PPC está só na sala, queixa-se do frio e puxa o lençol até o pescoço.

Por este exemplo verifica-se, novamente, que não houve a preocupação de informar o que acontecia às pacientes. Além disso, quando E voltou, não trouxe o cobertor para PPC.

\section{Exemplo V}

$E$ e $A E$ entram na sala. E pega a papeleta de PPC e diz a AE para levar a paciente.

PPC - "Estou com frio".

$\mathrm{AE}$ - "Por que a senhora não me disse, eu teria trazido cabertor".. 
AE empurra a maca pelo corredor do centro obstétrico.

$\mathrm{PPC}-“ A i . . . "$

$\mathrm{AE}$ - "O que está doendo, minha senhora?"

$E$ apaga as luzes da sala e encosta um pouco a porta.

Os exemplos revelam que, na maior parte das vezes. a interação profissional-paciente ocorreu nos momentos de realização de alguma tarefa. Houve alguma interação verbal entre PPC e PPN.

$O$ que se pode ainda notar é que as profissionais de enfermagem não tiveram o cuidado de informar as puérpuras sabre o que acontecia nos momentos da realização dos procedimentos técnicos. Com respeito aos procedimentos realizados, notou-se ainda que alguns controles necessários à avaliação das puérpuras não foram realizados (verificação da repleção vesical; das condições perineais e do sangramento vaginal). Além disso os controles vitais e da contração uterina foram realizados apenas uma vez e não a cada 10 ou 15 minutos como o preconizado pelos autores acima citados. Este fato sugere falhas nas variáveis ambientais programáticas enquanto fatores determinantes dos comportamentos das profissionais de enfermagem.

Considerando que este estudo constituiu uma primeira tentativa para verificar se as condiçōes ambientais de uma sala de recuperação pós-parto estavam congruentes com os objetivos que orientavam seu planejamento e montagem, parece válido concluir que esta. tentativa teve êxito uma vez que, de fato, mostra aspectos importantes dessas condições. Além disso, essa tentativa mostra um caminho no esforço para o aperfeiçoamento da assistência prestada - um esforço que pode ser estendido a outros ambientes, dependendo do interesse da instituição. Alguns pontos precisam, no entanto, ser ressaltados: uma única observação não é suficiente para se realizar qualquer tipo de intervenção; a observação constitui apenas um dos procedimentos possíveis, podendo ser complementada por entrevistas das pessoas envolvidas no ambiente, mapeamento comportamental, medidas do limiar de tolerância a ruídos e outros, dependendo da amplitude de objetivos da própria avaliação; este tipo de avaliação constitui apenas o primeiro passo ou talvez um atalho, no empreendimento de qualquer programa de intervenção. Caberá, em seguida, verificar em que medida as alterações apontadas poderão contribuir, de fato, para o aperfeiçoamento que se pretende.

SOLER, Z.A.S.G. \& MEJIAS, N.P. The postpartum recovery room as behavioral context: a temptative assessment. Rev. Esc. Enf. USP, São Paulo, 24(3):329-344, Dec. 1990 .

Considering the importance of environmental design as behavioral conetxt, a trial assesment was made in a postpartum recovery room, using systematic observation. Staft-patient and patient-patient interactions were also considerad. .Results indicate that alterations in some of the physical and programmatic environmental variables may contribute to improve patient assistance.

UNITERMS: Health facility environment. Recovery room. Delivery. 


\section{REFERÊNCIAS BIBLIOGRÁFICAS}

1. BARBOSA, L.A.H. Parto normal: evolução clínica do parto. In:

Obstetricia prática. 6. ed., Rio de Janeiro, Atheneu, 1981 . Cap. 4. p. 532-8.

2. CARVAlHo, A.A. de Planejamento de condições ambientais para produzir mudanças de comportamento. São Paulo, 1979. 188p. (Tese de doutorado - Instituto de Psicologia da USP).

3. CLAUSE, J. Efficient postpartum checks. Nursing, Sprinhouse, 2(10):24-7, Oct. 1972.

4. DANNA, M.F. \& MATOS, M.A. Ensinando observacão: uma introducão. São Paulo, Edicon, 1984. 90p.

5. DELASCIO, D. \& GUARIGNTO, A. Assistência ao parto. In: BRIQUETT, R. Obstetrícia normal. 3. ed. São Paulo, Sarvier, 1981. Cap. 21. p. 355-8.

6. GORAYEB, S.R.P. Alojamento conjunto e tradicional para mães e bebés na maternidade: um estudo comparativo. São Paulo, 1979. 144p. (Tese de doutorado - Instituto de Psicologia da USP).

7. GREenberg, E. The fourth stage of labor. Amer. J. Obst. Gynecol., Saint Louis, 52(1): 746-55, July 1946.

8. GRELLE, F.C. \& AMARAL, L.B. Fases clínicas do parto. In: —_ Obstetrícia. 2. ed. Rio de Janeiro, Atheneu, 1981. Cap. 11. p. 171-3.

9. HESTER, J.D. Post partum hemorrhage and revaluation of uterine packing. Obstet. Gynecol., New York, 45(5):501-3, May 1975.

10. HICKS, E.C. Obstetrical emergencies: a systematic aproach for nursing intervention. Nurs. Clin. North. Am., Philadelphia, 17(1):79-80, Mar. 1982.

11. INGSTAD, P.J. \& GUNNAR, G.K. Staff attitude changes after environment changes on a ward for psychogeriatric patients. Int. J. Soc. Psychiatry, London, 33(3):237-44, 1987.

12. KELLY, M.P. \& OSTREICHER, H. Environmental factors and outcome in hemineglected syndrome. Rehabil. Peychol., 30(1):35-7, 1985.

13. MAC DONALD et alif. Physical and social environment reprogramming as treatment for psychogeriatric patients. Int. J. Behav. Geriatr., 1(1):15-32, 1982.

14. MACKENZIE, I.Z. Induction of labor and post partum haemorrhage. Brit. Med. J., London, 1(6165):750, Mar. 1970.

15. MAURO, E. Engenharia de comportamento: uma contribuição à análise de dois equipamentos de uso hospitalar e à definição de ambiente terapêutico. São Paulo, 1980. 167p. (Tese de doutorado - Instituto de Psicologia da USP).

16. MC PHERSON, F.M. et alii. The behavioral effects on geriatric psychiatric inpatients o a move to a more spacious accomodation. Med. Sci. Psychol. Psychiatr., 13:964, 1985.

17. MOTTOS, T. \& MARETTI, M. Causas das hemorragias do quarto periodo do parto em nosso meio e suas medidas profiláticas. Matern. e Infânc., São Paulo, 34(3):453-64, jul./set. 1975.

18. NELSON, R.O. \& HAYES, S.C. Conceptual foundations of behavioral assessment. New York, Guilford Press, 1986. 523p.

19. NEME, B. Assistencia ao parto: $4^{\circ}$ periodo. Femina, Rio de Janeiro, 10(3):189-94, mar. 1982.

20. QUEIROZ, L.O. de S. Modificação de comportamento numa sala de pacientes crónicos utilizando sistemas de economia de fichas: controle das respostas de higiene matinal através de instruções orais e esmaecimentos. São Paulo, 1973. 231p. (Tese de doutorado - Instituto de Psicologia da USP). 
21. REZENDE, J. o parto: estudo clínico e assistência. In: Rio de Janelro, Guanabara-Koogan, 1974. Cap. 15. p. 284-94.

22. SCHAFER, S.C. Modifying the environment: special issue: alzheimer's disease. Geriatr. Nurs., New York, 6(3):157-9, 1985.

23. STAHLER, G.J. et alii. The evaluation of an environmental remodeling program on a psychiatric geriatric ward. J. Soc. Psychol., Provincetown, 123(1):101-13, 1984.

24. STEVE, B. Effects of furniture rearrangement on the atmosphere of wards in a maximum security hospital. Hosp. Community Psychiatr., Washington, 36(5):525-8, 1985.

25. STIRBULOV, S. de S.L. A interação pagem-criança numa creche: uma tentativa de avaliação. São Paulo, 1988. (Dissertação de mestrado - Instituto de Psicología da USP).

26. TWARDOSZ, S. Environmental organization: the physical, social and programmatic context behavior. In: HERSEN, $M$. et alii. Progress in behavior modification. Orlando, Academic Press, 1984. vol. 18. p. 123-61.

27. VERDERBER, S. \& REUMAN, D. Windows, views and health status in hospital therapeutic environments. J. Archit. Plann. Kes., 4(2):120-33, 1987.

28. WHITEHEAD et alii.' Objective and subjective evaluation of psychiatric redesign. Am. J. Psych., Washington, 141(5):639-44, 1984.

29. WinKEL, G.H. \& HOLAHAN, J. The environmental psychology of the hospital: 1s the cure worse than the illness? Special issue: beyond the individual: environmental approaches and prevention. Prev. Human. Serv., 4(1-2):11-33, 1985-86.

30. ZANNON, C.M.L. da C. O comportamento de crianças hospitalizadas e a rotina hospitalar: subsídios para a atuação do psicólogo junto à equipe de pediatria. 1981. 200p. (Tese de doutorado - Instituto de Psicologia da USP).

31. ZIEGEL, E. \& CRANLEY, M. Assistencia de enfermagem durante o parto. In:

Enfermagem Obstétrica. 8. ed. Rio de Janeiro, Interamericana, 1985. Cap. 21. p.404-6

Recebido em 10/11/89 